\title{
Clipping e a gestão em agência de comunicação
}

\section{Jucélia do Rocio Chiquim ${ }^{1}$ \\ Emerson de Castro Firmo da Silva ${ }^{2}$}

\section{Resumo}

Esta pesquisa propôs-se a analisar o processo de gestão jornalística de uma agência e assessoria de comunicação de Curitiba, considerando-se as práticas que envolvem o atendimento a assessorados. Especificamente para esta pesquisa escolheu-se a M\&C Comunicação que se destaca entre as agências por sua base tecnológica avançada. O método utilizado para a análise foi a combinação de entrevista com a direção da agência e observação do seu espaço físico e gestão dos processos que envolvem seus profissionais.

Palavras-chave: Comunicação organizacional, assessoria de comunicação, gestão, estudo de caso

\section{Abstract}

The aim of this research is to analyze the process of management in a communication and press consultancy agency from Curitiba, taking into consideration practices involving costumer services. For the present article, we choose a case study about M\&C Comunicação, well known among agencies for its advanced technological pattern. We used as a methodological basis a combination of interview with the agency's direction and the observation of the environment and managing process among its professionals.

Keywords: Organization communication, press consultancy, management, case study.

\section{Introdução}

Os estudos de jornalismo nas universidades contemplam, em geral, as apreciações sobre questões técnicas do campo jornalístico, considerando-se fundamental a aquisição desse conhecimento a fim de um exercício profissional adequado às normas e boas práticas exigidas pelas empresas. Completam esse quadro os conhecimentos do campo humanístico (filosofia, sociologia, história, antropologia), especialmente da ética. Mas é patente na atualidade a necessidade de os jornalistas compreenderem a importância de um outro campo de ação eminentemente jornalístico, o da gestão. Falta, inclusive, a percepção de que gestão é um item do campo jornalístico dos mais fundamentais para as empresas, sejam elas do ramo impresso, televisivo, radiodifusor ou agências de comunicação e assessorias.

Também é sintomático nos cursos de jornalismo que pouco tempo seja dedicado à reflexão sobre questões técnicas relacionadas ao campo da comunicação institucional, fato que se explica em parte pela compreensão de que essa não seria uma atividade do campo jornalístico. Em que pese a discussão ter sido de certo modo suplantada pela massiva presença

\footnotetext{
${ }^{1}$ Aluna do curso de Jornalismo da Universidade Positivo. E-mail: juceliarc@ yahoo.com.br.

2 Jornalista e mestra em História (UFPR), professor no curso de Jornalismo da Universidade Positivo. E-mail: teoriacastro@yahoo.com.br.
} 
de jornalistas em assessorias, conforme atesta a pesquisa sobre o Perfil do Jornalista Brasileiro ${ }^{3}$, ou até mesmo pelas recomendações das novas diretrizes curriculares ${ }^{4}$ dos cursos de jornalismo, vem prevalecendo a visão de que a atuação desse profissional, seja em veículos da mídia, seja em espaço institucional/empresarial, exige conhecimentos de gestão aplicados ao cotidiano de suas atividades.

Este artigo tem o objetivo de trabalhar nestas duas vertentes, pois se propõe a analisar o processo de gestão jornalística de uma agência e assessoria de comunicação de Curitiba, considerando-se as práticas que envolvem o atendimento a assessorados dos mais diversos ramos e setores da sociedade. Especificamente para este trabalho escolheu-se a M\&C Comunicação, empresa curitibana de assessoria de comunicação que se destaca entre as agências por sua base tecnológica avançada, pelo atendimento a clientes nacionais, incluindo ministérios do governo federal, e sua história, iniciada em 1986.

Os dados iniciais, em amplo questionário, foram coletados por alunos do $3^{\circ}$ ano do curso de Jornalismo da Universidade Positivo, no âmbito da disciplina Comunicação Institucional, produzindo conhecimento sobre como vem se dando na prática a gestão jornalística nessas agências e assessorias de comunicação. Dentro delas, o volume de concentração de profissionais jornalistas é, em geral, bem inferior ao de jornais, rádios e TVs, se for analisado o número por veículos e agências individualmente. O setor ${ }^{5}$, entretanto, é o que mais acolhe profissionais há anos, sendo o que mais vem crescendo e diversificando-se.

As práticas também são bastante diferentes, envolvendo desde contatos com a imprensa para divulgação e intermediação de notícias do assessorado, até planejamento estratégico de comunicação interna e externa. Tudo isso requer uma gestão específica, que se relaciona com o campo da administração, especialmente de recursos humanos e de materiais ou equipamentos, mas é muito mais afetada pelas lógicas jornalísticas de definição do que é a notícia sob a ótica de necessidade e interesse do assessorado, além de lógicas de planejamento estratégico do campo da comunicação. É semelhante, entretanto, no que tange os padrões técnicos e éticos da prática jornalística tradicional.

\footnotetext{
${ }^{3}$ UFSC e Fenaj publicaram em 2012 os resultados da pesquisa com 2731 jornalistas do país, identificando $40 \%$ dos profissionais atuando em assessorias de comunicação.

${ }^{4}$ Nas Novas Diretrizes Curriculares do curso de jornalismo é explícita a recomendação em relação ao Projeto Pedagógico para que adote "[...] incluir na formação as rotinas de trabalho do jornalista em assessorias a instituições de todos os tipos", assim como em outro ponto do documento propõe: "[...] Elaborar, coordenar e executar projetos de Assessoria jornalística a instituições legalmente constituídas de qualquer natureza [...]".

${ }^{5}$ Ainda conforme a Pesquisa Perfil do Jornalista Brasileiro, aproximadamente $40 \%$ dos profissionais atuam na área de assessoria, contra $55 \%$ nas mídias e $5 \%$ como professores.
} 
É exatamente aí que a gestão jornalística, embora desempenhada obrigatoriamente pelos profissionais da área, carece de estudo, já que parece ser realizada sem preparação adequada (seja nas universidades, seja nas próprias empresas), sem visão técnica específica ou perspectiva de uma possível intervenção técnico-científica, como já ocorre em outros campos da gestão.

Há menos de uma década Mafei identificava o começo desse problema ao afirmar que “[...] a própria matéria 'assessoria de imprensa' continua ausente, em grande parte, das próprias faculdades de Jornalismo!” (2004, p. 15). Seguramente essa não é mais a realidade da maioria das faculdades de jornalismo. Hoje os estudantes necessitam dar um passo além do conhecimento básico e ampliar seus conhecimentos dentro do curso, visando serem capazes de responder adequadamente ao mercado de trabalho externo às redações.

\section{Histórico e teorias}

As assessorias de imprensa apareceram no início do século XX nos Estados Unidos, quando Ivy Lee, um jornalista experiente, passou a trabalhar para John Rockfeller, “à época o mais impopular homem de negócios dos Estados Unidos. Foi escolhido a dedo, para ser o santo de um milagre impensável: conseguir que o velho barão do capitalismo selvagem, de odiado, passasse a ser venerado pela opinião pública americana” (DUARTE, 2006, p.34).

A partir desse período, ficou evidenciada a necessidade de que instituições, governos, empresas, homens públicos, todos que fazem parte da sociedade passassem a dialogar com a opinião pública, de certo modo, prestando contas de suas ações, atividades, atitudes, opiniões, posicionamentos que direta ou indiretamente atingiam essa mesma sociedade (DUARTE, 2006). As assessorias de imprensa fazem então o que se convencionou chamar de jornalismo empresarial ou organizacional, dando conta de variados tipos de trabalho direcionados a públicos distintos interna e externamente às empresas (REGO, 1984).

Especialmente no Brasil, esse trabalho tornou-se espaço de atuação de jornalistas, que hoje compõem boa parte dos profissionais na área. E, segundo Jorge Duarte, eles trouxeram características próprias do jornalismo das redações para as instituições, não só no sentido da agilidade de produção noticiosa ou a compreensão do campo da imprensa, mas também das preocupações éticas e de responsabilidade social (DUARTE, 2006, p. 81-102).

Nos últimos 20 anos a atividade foi consideravelmente ampliada, para o que se adotou a nomenclatura Assessoria de Comunicação, para abranger ações de comunicação interna, externa, com públicos segmentados, além de diversas atividades que direta ou indiretamente estão relacionadas com a área (DUARTE, 2006). 
A questão mais fundamental da atividade das Assessorias de Comunicação vem sendo a capacidade dos profissionais que nelas atuam de exercer um papel planejador estratégico, estabelecendo políticas de comunicação, envolvendo-se com os objetivos da organização (FERRARETO; KOPLIN, 2001).

É Maria Alzira Pimenta quem observa nos sistemas de informação gerenciais um espaço altamente promissor para a gestão da comunicação institucional e empresarial. As duas tendências, segundo ela, são: valorizar mais as crescentes capacidades técnicas de equipamentos high-tech.

Armazenar e processar um volume de dados cada vez maior e mais rápido, em princípio possibilitaria aos gerentes terem uma visão completa e sempre atualizada sobre os assuntos de interesse para a organização, permitindo tomar decisões eficazes on-line (em tempo real). Desse modo a ênfase está no volume e na velocidade de armazenamento, processamento, distribuição e renovação de informações (PIMENTA, 2002, p. 48).

Completa o raciocínio a segunda tendência, que enfatiza não a quantidade, mas o uso mais eficiente das informações em volumes relativamente pequenos, "sendo mais modesta e menos dispendiosa" (PIMENTA, 2002). Ainda segunda a autora,

\begin{abstract}
Para caracterizar essa abordagem Davenport (2001) usou a metáfora da ecologia da informação. O termo ecologia foi usado para a necessidade de considerar todos os aspectos da "vida" das informações em um ambiente complexo e específico (no caso informacional). Outro ponto importante é a centralização dos processos informativos nas pessoas, mostrando claramente que a tecnologia propriamente dita ocupa uma posição subordinada ao fator humano (PIMENTA, 2002, p. 48).
\end{abstract}

A partir dessa discussão teórica, o propósito desta pesquisa foi identificar como as assessorias e agências de comunicação estão atuando em Curitiba, especialmente no campo da gestão jornalística, diferente dos procedimentos verificados em jornais, rádios e TVs, em que a gestão se dá em outros moldes, adequados ao ponto de vista da busca da notícia pelos veículos. Para tal, foi escolhida a M\&C Comunicação, empresa existente desde 1986 e que atua em todas as áreas da comunicação institucional. Em especial, as tendências apontadas acima por Pimenta aparecem com forte evidência na atuação da agência objeto da pesquisa.

\title{
Metodologia
}

Diferentes procedimentos foram utilizados para coletar os dados sobre a gestão empregada na agência de comunicação $M \& C$. Primeiro foi feita uma entrevista com a fundadora e diretora da M\&C, Tereza Cristina Mello, também foi realizada uma análise de 
dados obtidos em entrevista de um livro sobre jornalistas empreendedores em que Mello conta o histórico de criação da agência. Por fim, fez-se uma observação do espaço da empresa e também o conhecimento sobre seu funcionamento. O método de levantamento de dados apoiouse ainda em uma pesquisa bibliográfica, em que foram obtidos aspectos teóricos sobre as agências de comunicação, assessorias de imprensa e tudo o que envolve essa área do jornalismo empresarial, incluindo a gestão das agências e assessorias.

\title{
Clipping como base
}

A M\&C Comunicação é uma empresa de comunicação integrada, cujo corpo de funcionários abrange profissionais de diversas áreas: relações públicas, publicitários, jornalistas, profissionais de tecnologia de informação, webdesigners. A M\&C tem cerca de 60 funcionários, e funciona 24 horas por dia, todos os dias, sendo que sábados e domingos têm turno de plantão, que conta com uma equipe reduzida.

A M\&C foi criada pela jornalista Tereza Cristina Mello em 1986, ou seja, a empresa tem 28 anos de experiência no mercado de agências de comunicação curitibano e nacional. Tereza Cristina foi assessora de imprensa de alguns órgãos e também assessorou a Superintendência de Recursos Hídricos no governo José Richa (1983-1986). Na questão da relação da empresa com o jornalismo, Mello afirma:

\begin{abstract}
$\mathrm{Eu}$ acho que quando ingressei no jornalismo, até a decisão de fazer jornalismo era uma coisa muito romântica. Mas o que a $M \& C$ foi construindo, eu acho que não deixou em nenhum momento de ter em foco o jornalismo, mas comecei a perceber a amplitude que é a questão da comunicação. Acho que os espaços começaram a ficar limitados pra que ficasse só na questão do jornalismo, da matéria. O comunicador tem um papel superimportante nessa sociedade. Você tem hoje "n" meios, "n" formas de trabalhar isso que são muito mais amplas do que pensar só na questão jornal. A gente via as outras profissões, publicidade e propaganda, até de uma forma muito preconceituosa, mas quando você passa a perceber a importância de trabalhar em sintonia com todas as áreas da comunicação é maior o seu resultado (MELLO, 2007, p. 68).
\end{abstract}

A base da M\&C foi o clipping 6 , ou seja, ela foi a primeira empresa no Brasil a lançar o clipping online, e em 1996 o serviço já era disponibilizado na internet. Foi a primeira empresa do Brasil a lançar o videoclipping e a primeira empresa a fazer auditoria de eleição. Em 2002, ela auditou a eleição presidencial, analisando 65 mil matérias, e detém o maior acervo de estudo

\footnotetext{
${ }^{6}$ Clipping era, até praticamente o final do século XX, o serviço de recortes de jornais e revistas que as agências prestavam a clientes interessados em saber como estavam sendo divulgadas suas notícias, sua marca, seus dirigentes na mídia impressa diariamente. Com o avanço tecnológico e a necessidade de mercado, esse serviço passou a ser feito também com reportagens de televisão, rádio e, atualmente, com tudo que é publicado na internet, seja em blogs, sites noticiosos ou institucionais e redes sociais.
} 
da imprensa até hoje. Segundo Tereza Cristina Mello, para dar conta da grande gama de informações na internet a $\mathrm{M} \& \mathrm{C}$ buscou uma alternativa diferenciada para a época, que foram os buscadores para diversos tipos e características: "Tem robô desenvolvido para aquele jornal específico, se não você não consegue pegar, mas é um misto de humano”. A partir disso a M\&C hoje consegue implantar um cliente em menos de duas horas e já inicia o clipping:

A gente desenvolveu uma tecnologia interna que a gente chama de job, que vai conversando com todas as ferramentas ali, opondo características, que é o que dá o grande diferencial e a questão de como você constrói a questão das palavras-chaves (MELLO, 2013).

Hoje a empresa trabalha meia-hora depois que a matéria saiu, sendo assim, depois desse tempo ela já está “clipada”, e se é há algo que merece atenção do cliente já é emitido um alerta para o mesmo, via celular. O clipping é realizado sob qualquer meio de comunicação e não abrange somente a internet. A M\&C traz as informações do clipping, estrutura, analisa, interpreta e emite essas informações, diariamente diversos clientes com boletins estratégicos de comunicação, com as recomendações aonde ele deve interagir com a mídia. Diariamente entra no banco de dados da M\&C uma média de quatro mil matérias, e pelo menos duas mil são analisadas e colocadas em boletins gerenciais para cada um dos clientes. Atuando com empresas de grande porte a $\mathrm{M} \& \mathrm{C}$, assim que contrata um cliente com esse aspecto, monta uma ilha com um grupo de atendimento que estará 24 horas no ar em atendimento ao cliente, inclusive sábado e domingo.

Muitos jornalistas não caracterizam as assessorias de imprensa como atribuição do jornalismo, questionando então a veracidade e a questão ética do profissional que trabalha nessa área. Visando esse aspecto, Mello afirma:

Primeiro acho que pra você manter a ética você tem que ver não o foco simplesmente no resultado financeiro. Na M\&C já tivemos várias situações de recusar clientes que não fazem parte da nossa filosofia, do que a gente acredita para a sociedade. Mas no nosso trabalho é fundamental que a gente tenha uma isenção pra tratar dessa questão da informação. Acho que manter a ética mesmo é você se recusar a fazer algumas coisas que não estão de acordo com sua filosofia de trabalho (MELLO, 2007, p. 73).

Mello aproveita, ainda, uma situação em que a questão ética da $M \& C$ foi colocada à prova para estabelecer seus princípios:

[...] a gente organizou um evento muito grande uma vez e o cliente acatou tudo. No segundo evento ele quis economizar, não no nosso custo, no custo deles. A M\&C está fora, porque dá para perceber quando eles se apropriam de alguma coisa, de alguns nomes, de algumas situações para ferir a sociedade. Então o que eu coloco: a M\&C é 
responsável pelo que ela está assinando, se ela está com determinado cliente, e se o cliente está com certas intenções, como era esse caso, a gente pula fora. Eu sou corresponsável se alguma informação está distorcida, se algum fato acabou acontecendo em função daquele evento que eu estou junto. Então eu não assino em baixo, e não caio junto (MELLO, 2007, p. 73).

Analisando o aspecto de as redações contratarem a cada dia menos jornalistas, uma alternativa para esses profissionais está sendo migrar para as assessorias, bem como exercer o papel de empreendedor. Mello avalia como positiva a questão do empreendedorismo para os profissionais da comunicação:

\begin{abstract}
As novas tecnologias da informação, que crescem no dia a dia, abrem oportunidades. Por exemplo hoje, se você trabalhar bem, pode vender conteúdo, como jornalista, pra canais alternativos. Você tem um espaço nas tevês comunitárias, tevês educativas que não conseguem preencher sua pauta, nas rádios do interior... A gente fica muito focado no mercado da capital ou de alguns dos grandes meios, mas você percebe um monte de gente precisando de conteúdo que você pode atender com uma mini produtora. (MELLO, 2007, p. 76).
\end{abstract}

Assim, a fundadora da $\mathrm{M} \& \mathrm{C}$ caracteriza um aspecto bem relevante para um jornalista se tornar um empreendedor, que é a coragem:

\footnotetext{
Primeiro, é um pouco de coragem, e saber que tem dias e tem meses que você pode ficar sem receber mesmo. A tua equipe tem que estar privilegiada. Eu acho que é a primeira coisa. Segundo, é achar que se você tem seu próprio negócio você vai trabalhar menos. Então é aquela coisa, não tem sábado, não tem domingo. É batata! Dia das Mães, aniversário de filho, final de ano, é dia de evento, é uma coisa impressionante.

Você sabe que vai ter que abrir mão de uma série de coisas. E querer, né? E acho que o mercado é rico na nossa área, não está se fechando; ao contrário, se abre pra "n" frentes. A questão é estar com informação, estar antenado e se doar. Seja financeiramente, seja em tempo, seja em espaço. E de estar percebendo as oportunidades (MELLO, 2007, p. 76).
}

Essa coragem - e que neste artigo se relaciona com a necessidade de estabelecer um tipo de gestão jornalística da agência de comunicação - faz parte da história da empresa analisada. Desde sua fundação, a M\&C prestava o serviço de clipping, mas em 1996 mudou parte do procedimento. O que era feito na base de papel, tesoura e cola (recortes de jornais e revistas colados em pequenos papéis que viriam a ser entregues aos clientes) passou a ser feito a partir de computadores, online.

A M\&C foi a primeira empresa no Brasil a lançar o clipping online. Então em 96, a gente já tinha o serviço entregue pela internet, bem no começo da internet, e foi a primeira empresa do Brasil a fazer isso. Foi também a primeira no Brasil a lançar o videoclipping, a primeira a fazer auditoria de eleição (MELLO, 2012). 
As eleições, no caso, tornaram-se um aspecto emblemático nesse processo de uso estratégico da informação para a gestão jornalística da Agência.

\begin{abstract}
Em 2002, a gente já auditou a eleição presidencial. Pra você ter uma ideia, na época a gente analisou 65 mil matérias, a gente tem o maior acervo de estudo da imprensa até hoje. Desde então a gente fez todas as eleições majoritárias, o único ano que eu optei por não fazer foi esse [2010].

Então a gente não fez, foi o primeiro ano que a gente ficou fora de fazer o trabalho técnico, mas a gente, aqui dentro, para nós, a gente analisou, porque não queremos perder acervo (MELLO, 2012).
\end{abstract}

A coragem surgiu justamente da percepção de futuro da empreendedora e da necessidade de ligar gestão e estratégia para prestar serviço a quem nem imaginava que precisaria dele com tal agilidade.

\begin{abstract}
Na verdade, a gente sempre criou aqui no departamento interno. Também não dá pra fazer comunicação sem você estudar o cenário, o mercado, o que está acontecendo. Então a gente sempre adotou o clipping como uma fonte de informação importante. Só que virou uma época em que a gente tinha uma casa inteira como acervo e não tinha coragem de jogar fora. Olhava aquela papelada amarelando e cada vez que você ia fazer um trabalho, fosse de prospecção, ou de trabalhar com o cliente uma inserção no mercado, ou fazer um evento, há sempre uma grande falta de informação. Daí a gente não tinha coragem de jogar fora (MELLO, 2012).
\end{abstract}

A empreitada exigiu, num primeiro momento, ajuda externa. Foi contratada uma empresa para desenvolver um tipo de robô que fosse capaz de fazer esse serviço de modo mais rápido e eficiente, processando milhões de dados ao mesmo tempo, cruzando-os sem que a mão humana obrigatoriamente precisasse intervir. Mas só muito recentemente é que esses robôs foram possíveis na prática.

\footnotetext{
$\mathrm{Na}$ época eram muitos dados (URLs). Hoje você tem os robôs que são muito mais precisos, mas na época era impossível. Só foi possível começar a fazer clipping com robô, na real - e que não dá pra ser $100 \%$ do robô - muito recente: é coisa de uns três anos pra cá. Então a gente tinha um misto, era recorta e cola na internet, pessoal lendo jornal e tal, só que a gente insere por dia, a base de dez mil matérias/dia no nosso banco de dados. Então a gente tem toda uma estrutura tecnológica muito forte, não só de acervo como de desenvolvimento (MELLO, 2012).
}

O resultado foi o acúmulo de todo tipo de informações com origem em todas as mídias, inclusive as eletrônicas, que podem servir a qualquer momento para mapear situações, identificar problemas de imagem em qualquer cliente. Sobre isso Mello afirma que a questão do acervo do banco de dados é uma tecnologia totalmente diferenciada.

Então imagine um Google inteligente que eu possa procurar por meio, por veículo, por data, por combinações de 15 a 20 palavras-chave e ele me traz em segundos, tudo 
marcadinho. Então hoje a gente deve estar com mais de 27 milhões de títulos não repetidos, tudo sistematizado do país. Tudo, desde 2000, 2001. Tem todos os jornais brasileiros, todas as revistas, todos os telejornais, os principais rádios, os principais blogs políticos e em específico alguns outros veículos, mas tudo sobre o país. E anterior até, desde 78,79, algumas coisas da história do país, como a questão das privatizações, tudo que a gente achou importante, digitalizou e colocou aqui dentro pra poder ter essa busca ágil e fácil (MELLO, 2012).

Quando a gestão da informação está intimamente ligada à gestão da agência de comunicação, os elementos se combinam e desse conhecimento surgem novas possibilidades. Mello conta que a base tecnológica e a base de dados (acervo) propiciaram uma gama de serviços que não eram avaliados até então como possíveis.

\begin{abstract}
Daí a gente começou a perceber que essa tecnologia, essa informação, trabalha muito com dados de interesse público. Vimos os desdobramentos e o poder que se tem de municiar de informação seja município, seja empresa. Então começamos a desenvolver serviços usando a base tecnológica que a gente tem. A gente desenvolveu o primeiro serviço integrado de informação aos municípios, com uma base de dados de todos os municípios do Brasil, todos os recortes segmentados. Foi outro know-how que desenvolvemos. Tenho prefeito, tenho partido, tenho tamanho, tenho IDEB, informações. Então a gente passa a coletar o Brasil inteiro, vários ministérios, vários portais, informações que digam respeito ao interesse daquele município, porque hoje grande parte dos municípios não utilizam as verbas e o recurso federal que o governo oferece por falta de informação (MELLO, 2012).
\end{abstract}

Com esse serviço foram sendo desenvolvidos outros, como o SIGleitor, SIGempresarial, SIGeducação $^{7}$ que a M\&C oferece para preparar escolas públicas e universidades com conteúdo que será dado nas provas do ENEM, do ENADE, entre outras possibilidades.

Hoje a gente consegue implantar um cliente em menos de duas horas. Nesse tempo já está saindo clipping dele. Porque a gente desenvolveu uma tecnologia interna que chamamos de job, que vai conversando com todas as ferramenta, opondo características, que é o que dá o grande diferencial e a questão de como construir as palavras-chaves. A Caixa $[\mathrm{CEF}]$, tem dia que chega a ter 1500 matérias/dia. Então cria-se várias estratégias, todas no foco da empresa cliente, de que isso aqui vai para destaque, para poder em primeira mão trabalhar os assuntos mais importantes. Então o que a gente sempre aliou: a tecnologia da informação a serviço da comunicação e do relacionamento (MELLO, 2012).

Um caso que pode exemplificar a atuação ampla e com o conceito de comunicação integrada, mas já no planejamento estratégico, foi o da Subsea $7^{8}$, empresa norueguesa que pretendia instalar-se em Pontal do Paraná, litoral do estado.

\footnotetext{
${ }^{7}$ Onde SIG significa Sistema de Informação Gerencial.

${ }^{8}$ A multinacional norueguesa Subsea 7 do Brasil é dona de uma área de 2,7 mil hectares e planejava construir e operar uma unidade de soldagem e revestimento de dutos de exploração marítima em Pontal do Paraná. Mas a Justiça Federal entendeu que a obra poderia produzir impacto em comunidades indígenas e, por isso, o processo de licenciamento deveria ser conduzido pelo Ibama. A ação civil pública havia sido
} 


\begin{abstract}
A gente usou a integração de fato: web, relacionamento, evento, informação estratégica. A Subsea 7, que é uma empresa de submarinos, estava querendo se instalar aqui no Pontal. Então ela comprou uma área de 2700 hectares, onde ia usar menos de $3 \%$, que é uma área de solda, e inserir o Paraná no mapa do pré-sal e os outros 2600 hectares e poucos era colocado pra preservação permanente. Teve um projeto que era uma quebra de paradigma, um projeto para os índios que era uma coisa fantástica, mas por problemas políticos está num [impasse] (MELLO,2012).
\end{abstract}

Segundo Mello (2012), a empresa geraria 600 empregos diretos, e a M\&C entrou com todas as áreas de mapeamento. O objetivo era apresentar a empresa no litoral, mas a instalação de uma outra empresa, alguns anos antes, complicou as coisas. Ao chegar, de imediato, a empresa teria colocado três mil funcionários lá dentro, para uma coisa que seria provisória. $\mathrm{O}$ trabalho da $\mathrm{M} \& \mathrm{C}$, segundo explica a diretora da empresa, foi procurar esclarecer os benefícios à população.

\begin{abstract}
Então a gente fez toda a parte de apresentar a empresa, promover o relacionamento com a comunidade, com a imprensa, com as autoridades dos três poderes... todos os agentes que eram importantes no processo. Divulgamos os benefícios econômicos, ambientais, para realizar as audiências públicas.

Quando a gente viu a dificuldade de trabalhar com a população, foi feita uma grande pesquisa de campo. Mapeou-se tudo, levantou-se quais eram as lideranças locais, instituições atuantes, formadores de opinião, as características socioeconômicas da região. Esses trabalhos todas serviram de base para as ações institucionais. Também foi amparado pelo monitoramento de mídia, por exemplo, na questão da própria característica política local. Era uma junção de fatores lá, uma coisa impressionante. Então o monitoramento de mídia nos ajudou muito nessa história (MELLO, 2012).
\end{abstract}

\title{
Auditoria de imagem
}

Mas nem só em clipping e base de dados baseia-se o processo de atuação da agência de comunicação. Outros serviços ajudam na gestão das contas dos clientes, sobretudo os maiores. A auditoria de imagem é um destes pontos, que a tecnologia desenvolvida na $\mathrm{M} \& \mathrm{C}$ propiciou um tipo de atendimento incomum na área. O serviço, quando comparado numa concorrência da qual a agência participou, era muito mais ágil que o usual de mercado.

Por exemplo, quando a gente começou a fazer auditoria, inclusive do Banco do Brasil, que foi a partir de uma concorrência, as empresas trabalhavam a televisão num relatório mensal. Eles não colocavam no gerenciamento, então faziam uma análise diária, mandavam em papel (MELLO, 2012). 
A novidade foi tal que o vencedor inicialmente da licitação acabou não conseguindo efetivar-se; a licitação foi suspensa, e reaberta novamente acatando a proposta da $\mathrm{M} \& \mathrm{C}$, mais avançada, com tecnologia exclusivamente desenvolvida dentro da empresa.

\begin{abstract}
Você, cliente, tem que correr atrás do seu prejuízo e muito rápido. Então a M\&C foi pioneira também em incluir na auditoria de imagem a parte de televisão, que nenhuma empresa trabalhava com isso, até porque a gente tem a tecnologia de fazer.

Então hoje a gente trabalha e daqui meia hora depois que a matéria saiu no ar ou uma matéria de rádio, ela já está cortada, disponível e se for desgaste já põe em alerta o cliente pelo celular, em qualquer lugar. Todas as nossas tecnologias, hoje, elas podem ser vistas por qualquer meio, seja celular, iphone, tablet, qualquer dessas coisas (MELLO, 2012).
\end{abstract}

E por que agilidade nesse trabalho parece tão importante? Quem trabalha com comunicação sabe que uma crise instala-se tão forte e tão rapidamente quanto mais pessoas em pouco tempo identificam um problema que atinge a coletividade. Para Mello (2012), "a auditoria de imagem tem todo um processo de trabalho para poder fazer isso: um raio-X de tudo que saiu na imprensa, onde você tem assuntos que podem gerar desgaste". Segundo a jornalista, se o problema vincula-se ao cliente (seja público ou privado), ele terá necessidade de ter acesso a esses dados o mais rápido possível, e tomar providências.

A responsabilidade social, mesmo que indiretamente, também surge no trabalho de gestão jornalística da agência de comunicação. A Blitz da Cidadania, um projeto formulado para a Polícia Militar do estado aponta como as informações obtidas pelo processo de auditoria de imagem - a partir da base de dados - levou a polícia a rever posturas e ações junto a população.

Para formular a Blitz da Cidadania, a gente antes identificou que tinha um problema muito grande lá atrás com a questão da polícia. Então foi feita uma apresentação, com toda uma série de informações da imprensa, mostrando e fazendo o detalhamento. Mostramos como é que eles eram percebidos pela população: muito mal. E quando eles tinham ações positivas a população também sabia reconhecer. Daí pediram pra gente um projeto e desenvolvemos a Blitz da Cidadania: todos os órgãos da polícia levando trabalho para a comunidade (MELLO, 2012).

Por fim, a gestão jornalística da agência M\&C também coloca a tecnologia para auxiliar tanto clientes que contratam a empresa, como também para atender a imprensa, de maneira a estabelecer um relacionamento que pode ser definido como ganha-ganha.

Então a gente começou a trabalhar determinado conteúdo, gravidez na adolescência, por exemplo. Geramos conteúdo para as rádios comunitárias e rádios comerciais pequenas de todo o Brasil, segmentada. Fez isso a partir de um canal desenvolvido aqui, que é o disparador de e-mail. Consigo saber o que foi aberto, o que foi baixado, o que não foi baixado, o que eles viram. Ah, começa a interessar? Então aquelas peças têm mais interesse, começa-se a segmentar. A própria ferramenta faz pesquisa e leva esse conteúdo de interesse para os respectivos veículos. Começamos o trabalho com seis mil rádios no país, no começo dois a três por cento veicularam, mas chegamos no 
final com setenta por cento das rádios veiculando conteúdo de interesse da empresa cliente (MELLO, 2012).

\section{Considerações finais}

O resultado obtido com esta pesquisa aponta inicialmente para a compreensão da comunicação institucional como um campo em que historicamente os jornalistas vêm atuando no Brasil, e por isso estão construindo ou ajudando a construir modelos próprios de atuação. A visão adotada na agência M\&C Comunicação - que parte da informação como base de trabalho para todas as ações - sugere uma visão gestora estratégico-empresarial estabelecida com altos investimentos em desenvolvimento tecnológico para formação de bases de dados próprias sobre tudo que possa servir ao mapeamento de temas relacionados a seus clientes assessorados.

O segredo aparece no melhor uso da informação que é pública, mas dificilmente agrupada adequadamente (base de dados), visando inúmeras aplicações no planejamento estratégico e integrado da comunicação. São ações que envolvem projetos específicos, mas que também significam direta ou indiretamente responsabilidade social, inovação e eficiência na solução de gestão de crises de imagem, até o atendimento de profissionais da imprensa e veículos de maneira segmentada, sendo estes também uma espécie de clientes a partir de seus interesses que se relacionam aos clientes da $\mathrm{M} \& \mathrm{C}$.

Esse modelo de trabalho mostra como é possível aliar uma visão jornalística às práticas de assessoria de comunicação, processando dados de maneira a potencializar o planejamento e a gestão estratégica de comunicação. Mais que isso, propicia unir essas práticas à responsabilidade social, tão fundamentais aos profissionais jornalistas.

\section{Referências}

BERGAMO, A.; MICK, J. (coord.); LIMA, S. Perfil do Jornalista Brasileiro -UFSC/FENAJ, 2012. Disponível em http://www.fenaj.org.br/.

DUARTE, J. Assessoria de Imprensa e relacionamento com a mídia - Teoria e Técnica. São Paulo: Editora Atlas, 2006.

KOPLIN, E.; FERRARETO, L.A. Assessoria de Imprensa - Teoria e Prática. Porto Alegre: Sagra Luzzatto, 2001.

MAFEI, M. Assessoria de Imprensa: Como se relacionar com a mídia. São Paulo: Contexto, 2004.

MELLO, C. in OLIVEIRA FILHA, E.A. e SILVA, E.C.F. Entrevista Coletiva 4. Curitiba: PósEscrito, 2007. 
MELLO, C. Depoimento concedido em novembro de 2012 a Camila Cassins, à época responsável pelo projeto de Iniciação Científica que gerou este artigo.

MELLO, C. Depoimento concedido em junho de 2013 a Jucélia Chiquim, responsável pelo projeto de Iniciação Científica que gerou este artigo.

NASSAR, P. (Org.) Comunicação Interna: a força das empresas. São Paulo: Editora ABERJE, 2003

NASSAR,P. Evolução da Comunicação Organizacional brasileira no contexto da administração in MARCHIORI, M. Comunicação e Organização: reflexões, processos e práticas. São Caetano do Sul: Difusão Editora, 2010

Novas Diretrizes Curriculares do curso de Jornalismo, em http://portal.mec.gov.br/dmdocuments/documento_final_cursos_jornalismo.pdf - documento acessado em 03 de dezembro.

PIMENTA, M.A. Comunicação Empresarial. Campinas: Editora Alínea, 2002

REGO, F.G.T. - Jornalismo Empresarial - Teoria e Prática. São Paulo: Summus Editorial, 1984. 